\title{
Effect of Irradiation Wavelength on Kinetics of Direct Photodegradation of Estrone
}

\author{
Yiwei Deng, Paul Diven, and Padma Kadiyala
}

\begin{abstract}
Natural and synthetic estrogens present a potential threat to aquatic life. This is due to their alarming effects on reproduction and developmental processes of aquatic organisms. These estrogens disrupt the organisms' endocrine systems and decreased their fertility. The estrogens reach the aquatic environment through urban and industrial waste discharges. Irradiation of the wastewater under ultra-violet light showed that these estrogens could be degraded. In this study, Estrone (E1) was chosen as a representative of the estrogens. The photochemical behavior of $\mathrm{E} 1$ was investigated under ultra-violet irradiation at $254 \mathrm{~nm}$ and $350 \mathrm{~nm}$. The photodegradation of E1 yielded several intermediates. The concentrations of estrone and the intermediates were monitored during photodegradation using a high performance liquid chromatography (HPLC) method. The photodegradation of E1 at both wavelengths followed pseudo-first-order kinetics with respect to E1 concentration. The HPLC chromatograms indicated that three peaks were sequentially formed with time through plausible consecutive reactions. Further study is needed to identify the reaction intermediates/products in order to propose the detailed reaction mechanisms.
\end{abstract}

Index Terms - Estrone, photodegradation, steriod estrogens.

\section{INTRODUCTION}

The ubiquitous presence of emerging endocrine disrupting chemicals (EDCs) has become growing concerns due to their detrimental effects on human and animal endocrine systems [1]-[3]. Many of them can interfere with the normal function of hormones by interacting with the endocrine system [1]. They present a potential threat to aquatic life and human health. EDCs enter the aquatic environments mainly through sewage discharge and animal waste disposal due to both human and animal excretions [2], [3]. Among the EDCs, natural estrogens (e.g., estrone (E1), 17 $\beta$-estrodiol (E2)) are of particularly concern due to their high estrogenic activities.

Despite extremely low concentrations $(\mathrm{ng}-\mu \mathrm{g} / \mathrm{L})$ detected in aquatic environments, they are largely associated with alarming effects on reproduction and developmental processes of animals and aquatic organisms such as feminization, sex reversal and decreased fertility [1], [4]-[6].

\footnotetext{
Manuscript received May 10, 2014; revised July 8, 2014. This work was supported in part by the Department of Natural Sciences and the Student Research Grants (grant awarded to P. Diven to support the project) of the University of Michigan-Dearborn, Dearborn MI 48128. The Reaction Kinetics of Photodegrading Estrone at $245 \mathrm{~nm}$ and $350 \mathrm{~nm}$ Irradiation.

The authors are with the Department of Natural Sciences, University of Michigan-Dearborn, MI, 48128 Michigan (e-mail: dengy@umich.edu, pdiven@umich.edu,pkadiyal@umich.edu).
}

E1 is one of the most commonly found estrogens in human wastes, wastewater and surface water [2], [3], [6]. The chemical structure of E1 is presented in Fig. 1.

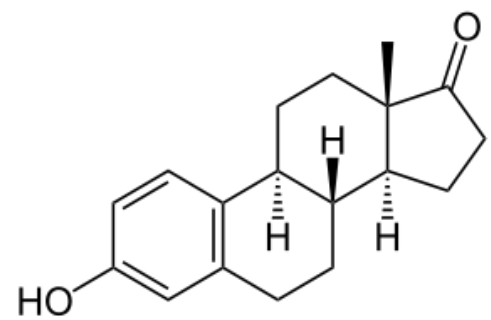

Fig. 1. Chemical structure of estrone (E1) used in the study.

As E1 has considerable sunlight absorption in the wavelength region of $250-320 \mathrm{~nm}$, it is expected that direct photolysis plays a critical role in its diminution in aquatic environments [7].

There have been ongoing investigations on the photodegradation of estrogens during the past two decades [7]-[10]. Many focused on direct photolysis by sunlight and indirect photolysis in the presence of natural photoreactive substances such as humic substances (HS), iron(III) carboxylates. Few studies have been dedicated to compare the kinetics of degradation of E1 under different irradiation wavelengths. Little is known about kinetics of formation and degradation of reactions intermediates in the course of photodegradation of E1.

This study aims to investigate the photochemical behavior of E1 under two different wavelengths (i.e., $254 \mathrm{~nm}$ and 350 $\mathrm{nm}$ ) of irradiation. In this context, photodegrdation kinetics of E1 as well as its intermediates was studied.

\section{MATERIALS AND METHODS}

\section{A. Materials}

All chemicals, except noted, were analytical-reagent grade and used without further purification. E1 (> 99\%) and acetonitrile $\left(\mathrm{CH}_{3} \mathrm{CN}\right.$, HPLC grade) were purchased from Sigma-Aldrich (St. Louis, MO, USA). Water was HPLC grade from Fisher Scientific (Fair Lawn, NJ, USA).

\section{B. Analytical Methods}

Analysis of E1 was carried out using a high performance liquid chromatography (HPLC) system equipped with a photodiode array detector (Shimadzu, Columbia, MD, USA) and a C8 column $(5 \mu \mathrm{m}, 150 \mathrm{~mm} \times 4.6 \mathrm{~mm}$, Alltech Associates, Waltham, MA, USA). The mobile phase was prepared by mixing acetonitrile with water in a 1:1 ratio. Prior to its use, the mobile phase was degassed for $25 \mathrm{~min}$. in an ultrasonic water bath (Branson 2510, Branson Ultrasonic, Danbury, CT, 
USA). An isocratic elution was used to separate E1 and its reaction intermediates/products. The flow rate was 0.8 $\mathrm{mL} / \mathrm{min}$ and the detection wavelength was $280 \mathrm{~nm}$. The temperature of the column compartment was kept at $24 \pm 1^{\circ} \mathrm{C}$. The injection volume was $20 \mu \mathrm{L}$.

The stock solution of E1 $\left(8.0 \times 10^{-4} \mathrm{M}\right)$ was prepared by dissolving the solid estrone in a $50 \%(\mathrm{v} / \mathrm{v})$ acetonitrile aqueous solution. A series of E1 standards were prepared by diluting appropriate volumes of the stock solution with the $50 \%$ acetonitrile solution, and then analyzed by HPLC. Each individual sample was injected twice, thus giving two sets of results used for the average peak calculation. A standard curve of E1 was constructed by plotting the average peak areas of E1 from their chromatograms as a function of E1 concentrations. A good linear relationship $(y=2969.3 x)$ was obtained up to $420 \mu \mathrm{M}$ with the regression coefficient of 0.992. The detection limit for E1 was $6.4 \mu \mathrm{M}$ based signal-to-noise ratio $(\mathrm{S} / \mathrm{N})$ of three.

\section{Photolysis Experiments}

A Rayonet photoreactor (RPR-100, Southern New England Ultraviolet Company, Branford, CT, USA) was used for irradiation. The reactor cavity held a quartz reaction vessel (length: $50 \mathrm{~cm} \times$ diameter: $10 \mathrm{~cm}$ ) equipped with a cold finger where tap water was circulated through the vessel to provide cooling of the solution in the vessel. The cold finger also provided a gas outlet that vented gases produced by reactions. The temperature was kept at $18 \pm 2{ }^{\circ} \mathrm{C}$ as tap water circulated through the cold finger. A monochromatic irradiation condition was achieved by selecting lamps with a desired wavelength of $254 \mathrm{~nm}$ or $350 \mathrm{~nm}$ (Southern New England Ultraviolet Company, Branford, CT, USA).

A solution of E1 $\left(3.8 \times 10^{-4} \mathrm{M}\right)$ was freshly prepared by diluting the stock solution of E1 with the $50 \%$ acetonitrile solution. The $\mathrm{pH}$ of the solution was $6.0 \pm 0.5$. The solution $(200 \mathrm{~mL})$ was transferred to the quartz vessel for photolysis. Samples were taken at various time intervals and analyzed for E1 as well as the reaction intermediates/products by HPLC. With the detection limit of HPLC, a higher E1 concentration than those detected in the environments was used to ensure quantitative measurements of E1 in the photodegradation process. E1 has a very low solubility in water. To enhance its solubility, a $50 \%$ acetonitrile aqueous solution was used to prepare all of the E1 solutions used in this study.

In addition to the HPLC analysis, the absorption spectrum of an E1 solution $\left(3.8 \times 10^{-4} \mathrm{M}\right.$ in $\left.50 \% \mathrm{CH}_{3} \mathrm{CN}\right)$ prior to photolysis was measured by an UV-Visible spectrophotometer (Evolution Array, Thermo Scientific, Waltham, MA).

\section{Calculation of the Irradiation Energies}

The irradiation energies associated with $254 \mathrm{~nm}$ and 350 $\mathrm{nm}$ electromagnetic radiations are calculated by the Planck's equation:

$$
E=\frac{h c}{\lambda}
$$

where $E$ is the single quantum energy $(\mathrm{J}), h$ is the Planck's constant, $6.63 \times 10^{-34} \mathrm{~J} \cdot \mathrm{s}, c$ is the speed of light, $3.00 \times 10^{8}$ $\mathrm{m} / \mathrm{s}$, under vacuum, and $\lambda$ is the wavelength $(\mathrm{m})$ [11]. The energies are $472 \mathrm{~kJ} / \mathrm{mol}$ photons and $0.977 \mathrm{~kJ} / \mathrm{mol}$ photons for $254 \mathrm{~nm}$ and $350 \mathrm{~nm}$, respectively.

\section{RESUlTS AND DISCUSSION}

Fig. 2 shows the comparison of E1 photodegradation at $254 \mathrm{~nm}$ and $350 \mathrm{~nm}$. The concentration of E1 was decreased exponentially at $245 \mathrm{~nm}$ with $98.8 \%$ of E1 degraded within 10 minutes. The degradation of E1 at $350 \mathrm{~nm}$, however, proceeded in a much slower rate with only $3.5 \%$ of E1 degraded within 10 minutes. In general, direct photolysis occurs because of the absorbance of photons of certain energy by the substrate (e.g., E1) [7], [9]. The direct photolysis also depends on intensity of irradiation energy, rate of light absorption and reaction quantum yield of the excited state [7], [9].

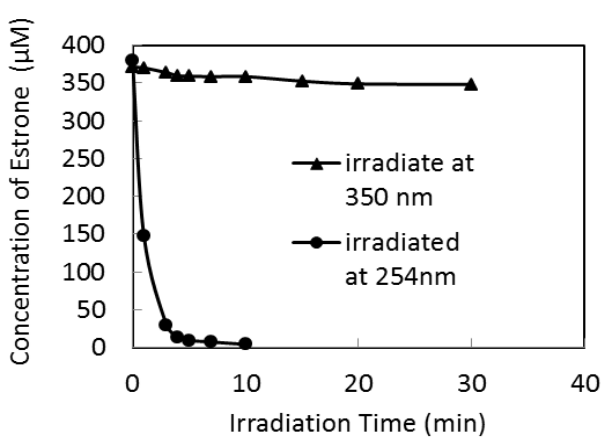

Fig. 2. Comparison of change in concentration of $\mathrm{E} 1\left(3.8 \times 10^{-4} \mathrm{M}\right.$ in $50 \%$ $\mathrm{CH}_{3} \mathrm{CN}$ ) irradiated at $254 \mathrm{~nm}$ and $350 \mathrm{~nm}$ with time.

E1 exhibits considerable absorption in the 250-325 nm wavelength region as shown in Fig. 3.



Fig. 3. The absorption spectrum of an E1 aqueous solution $\left(3.8 \times 10^{-4} \mathrm{M}\right.$ in $50 \% \mathrm{CH}_{3} \mathrm{CN}$ )

It significantly overlaps with the irradiation wavelength of $254 \mathrm{~nm}$, thereby promoting the absorption of photons at 254 $\mathrm{nm}$ and triggering the degradation of E1.

In addition, the energy associated with $254 \mathrm{~nm}$ electromagnetic irradiation is $472 \mathrm{~kJ} / \mathrm{mol}$ which is greater than the average bond energy of a C-C $(347 \mathrm{~kJ} / \mathrm{mol}), \mathrm{C}-\mathrm{O}$ $(351 \mathrm{~kJ} / \mathrm{mol}), \mathrm{C}-\mathrm{H}(414 \mathrm{~kJ} / \mathrm{mol}$, or $\mathrm{O}-\mathrm{H}$ bond $(460 \mathrm{~kJ} / \mathrm{mol})$ bond [12]. The irradiation energy was sufficient to break any of these bonds present in an E1 molecule. In contrast, the absorption band of E1 was not significantly overlapped with the irradiation wavelength of $350 \mathrm{~nm}$. The energy associated with $350 \mathrm{~nm}$ electromagnetic radiation is $0.977 \mathrm{~kJ}$ which is not sufficient to break the bonds listed above.

In the course of the photodegradation of E1, the peaks of E1 and reactions intermediates were monitored by HPLC. 
Prior to the irradiation, only an estrone peak was recorded (Fig. 4a) on the chromatogram, whereas three unidentified peaks were recorded at $10 \mathrm{~min}$ of irradiation at $254 \mathrm{~nm}$ (Fig. 4b). This observation indicates that at least three intermediates/products were formed through the photochemical reaction described below:

$$
\mathrm{E} 1+h v-----\rightarrow \text { intermediates/products }
$$

The decrease in concentration of E1 was accompanied with increasing concentrations of intermediates with time, reaching plateaus and then decline with time (Fig. 5). Evidently, the photodegradation of E1 involves several consecutive reactions with the intermediates/products formed and consumed in a sequential order. Further study on the product identification is needed to propose detailed reaction mechanisms.
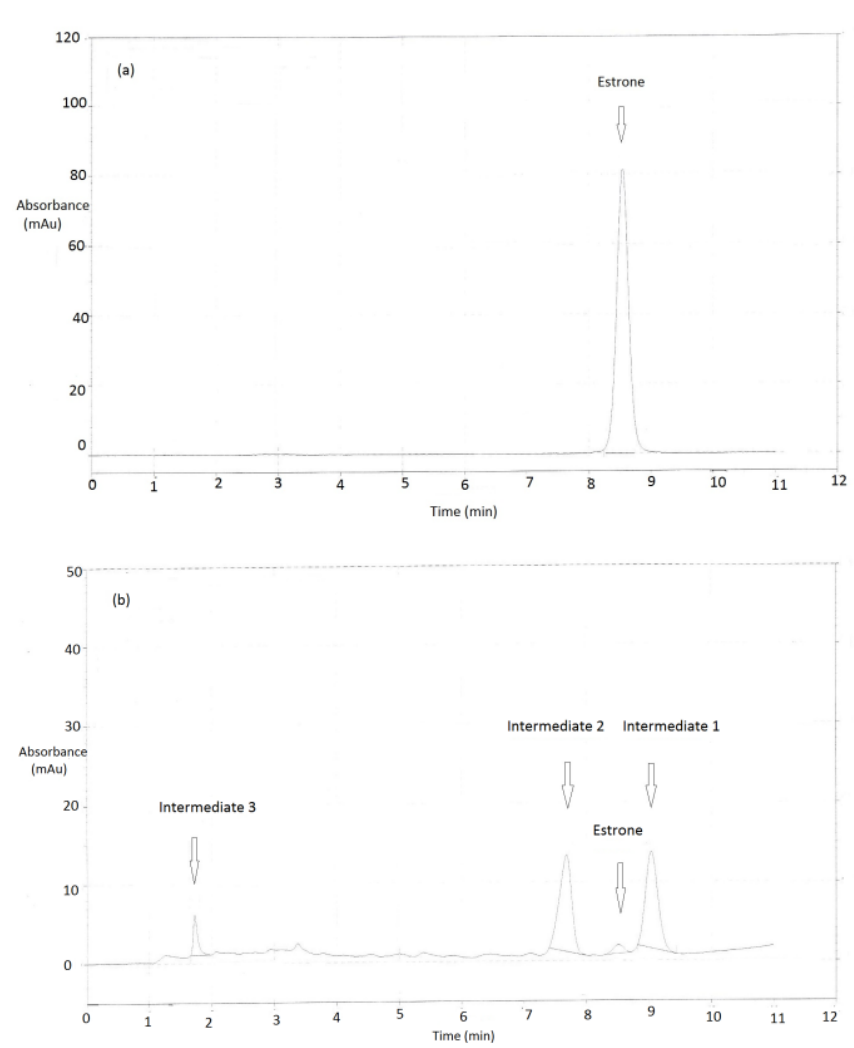

Fig. 4. (a) A HPLC chromatogram of E1 before the irradiation and (b) a chromatogram of $\mathrm{E} 1$ and its reaction intermediates after 10 minutes of irradiation at $254 \mathrm{~nm}$.

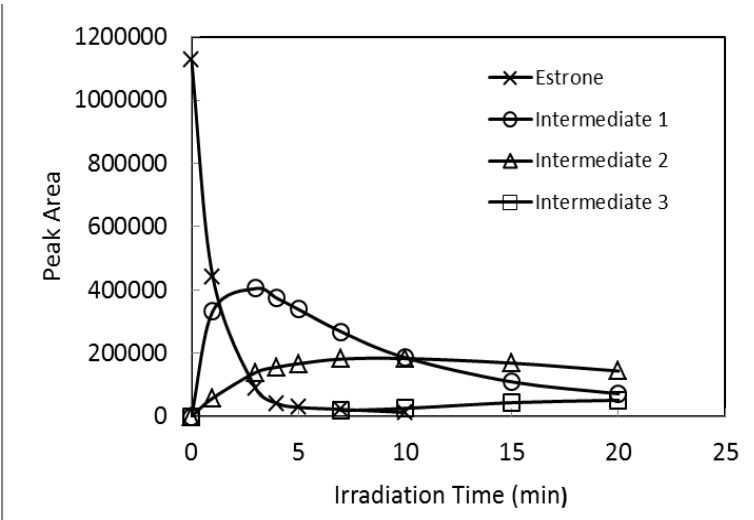

Fig. 5. The decrease of $\mathrm{E} 1\left(3.8 \times 10^{-4} \mathrm{M}\right.$ in $\left.50 \% \mathrm{CH}_{3} \mathrm{CN}\right)$ and evolution of the intermediates with time at $254 \mathrm{~nm}$.
In the early stage of the photodegradation, E1 was the predominate species that underwent the degradation. A plot of $\ln \left(C / C_{0}\right)$ against reaction time $(t)$ is shown in Fig. 6. It indicates the reaction follows pseudo-first order kinetics with respect to E1 concentration at the both irradiation wavelengths as given by

$$
\ln \left(\frac{C}{C_{0}}\right)=-k t
$$

where $C_{0}$ and $C$ are the concentrations of $\mathrm{E} 1$ at time zero and any given time, respectively. $t$ is the reaction time ( $\mathrm{min}$ ) and $k$ is the pseudo-first-order degradation rate constant $\left(\mathrm{min}^{-1}\right)$. The half-life $\left(t_{1 / 2}\right)$ of E1 can be calculated by

$$
t_{1 / 2}=\frac{\ln 2}{k}
$$

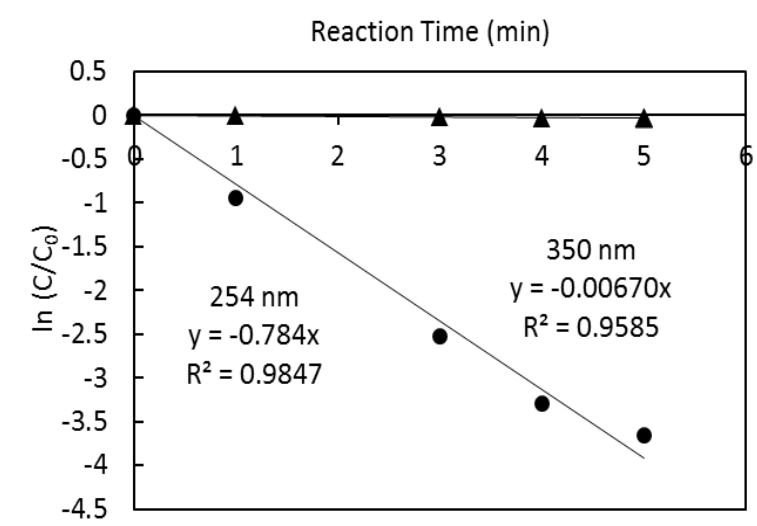

Fig. 6. The photodegradation of E1 at $254 \mathrm{~nm}$ and $350 \mathrm{~nm}$ follows the first-order kinetics in E1 with the rate constants of $0.784 \mathrm{~min}^{-1}$ and 0.00670 $\min ^{-1}$ at $254 \mathrm{~nm}$ and $350 \mathrm{~nm}$, respectively.

Table I summarizes the kinetic parameters of rate constant and half-time of photodegradation of E1 at the both

\begin{tabular}{|c|c|c|}
\hline $\begin{array}{c}\text { Wavelength } \\
(\mathrm{nm})\end{array}$ & $\begin{array}{l}\text { Rate Constant } \\
\qquad\left(\min ^{-1}\right)\end{array}$ & $\begin{array}{l}\text { Half-life } \\
\text { (min) }\end{array}$ \\
\hline 254 & 0.784 & 0.884 \\
\hline 350 & 0.00670 & 103 \\
\hline
\end{tabular}
irradiation wavelengths.

TABLE I: Kinetic PARAMETERS OF THE PHOTODEGRADATION OF E1 (3.8 ×

\section{CONCLUSIONS}

The direct photodegradation of E1 occurs under irradiation at $254 \mathrm{~nm}$ and $350 \mathrm{~nm}$. The rate of photodegradation of E1 depends strongly on wavelength of irradiation. The initial stage of the reaction follows a first-order kinetics model with respect to the $\mathrm{E} 1$ concentration. The rate constants are 0.784 $\mathrm{min}^{-1}$ and $0.0670 \mathrm{~min}^{-1}$ for $254 \mathrm{~nm}$ and $350 \mathrm{~nm}$, respectively. The degradation of E1 proceeded faster at $254 \mathrm{~nm}$ than at 350 $\mathrm{nm}$. This is due to the greater energy associated with photons at $254 \mathrm{~nm}$ than at $300 \mathrm{~nm}$, and the significant overlap of the absorption spectrum of E1 with the UV light at $254 \mathrm{~nm}$. The half-life values of the reaction were estimated as 0.884 minutes and 103 minutes at $254 \mathrm{~nm}$ and $350 \mathrm{~nm}$, respectively. The reaction likely involves in several consecutive 
reactions with their intermediates/products formed and consumed in a sequential order. Further study is needed to identify the reactions intermediates/products in order to propose the detailed reaction mechanisms.

\section{REFERENCES}

[1] S. Jobling, M. Nolan, C. R. Tyler, G. C. Brighty, and J. P. Sumpter, "Widespread sexual disruption in wild fish," Environ. Sci. Technol. vol. 32, pp. 2498-2506, 1998.

[2] D. Rajraman, E. L. Williams, A. C. Layton, R. T. Burns, J. P. Easter, A. S. Daugherty, M. D. Mullen, and G. S. Sayler, "Estrogen content of dairy and swine wastes," Environ. Sci. Technol., vol. 38, pp. 3567-3573, 2004.

[3] M. J. Benotti, R. A. Trenholm, B. J. Vanderford, J. C. Holady, B. D. Stanford, and S. A. Snyder, "Pharmaceuticals and Endocrine Disrupting Compounds in U.S. Drinking Water," Environ. Sci. Technol., vol. 43, pp. 597-603, 2009.

[4] Y. Zuo, K. Zhang, and Y. Deng, "Occurrence and Photochemical Degradation of $17 \beta$-Ethinylestradiol in Acushnet River Estuary," Chemosphere, vol. 63, p. 1583, 2006.

[5] W. Zheng, S. R. Yates, and S. A. Bradford, "Analysis of steroid hormones in a typical dairy waste disposal system," Environ. Sci. Technol., vol. 42, pp. 530-535, 2008.

[6] R. J. Williams, A. C. Johnson, J. J. L. Smith, and R. Kanda, "Steroid estrogens profiles along river stretches arising from sewage treatment works discharges," Environ. Sci. Technol., vol. 37, pp. 1744-1750, 2003.

[7] R. R. Chowdhury, P. Charpentier, and M. B. Ray, "Photodegradation of estrone in solar irradiation," Ind. Eng. Chem. Res., vol. 49, pp. 6923-6930, 2010.

[8] S. K. Atkinson, V. L. Marlatt, L. E. Kimpe, D. R. Lean, V. L. Trudeau, and J. M. Blais, "Environmental factors affecting ultraviolet photodegradation rates and estrogenicity of estrone and ethinylestradiol in natural waters," Arch. Environ. Contam. Toxicol., vol. 60, pp. 1-7, 2011.

[9] Y. Chen, K. Zhang, and Y. Zuo, "Direct and indirect photodegradation of estriol in the presence of humic acid, nitrate and iron complexes in water solutions," Sci. Total Environ., vol. 463-364, pp. 802-809, 2013.

[10] A. Y. Lin and M. Reinhard, "Photodegradation of common environmental pharmaceuticals and estrogens in river water," Environ. Toxicol. Chem., vol. 24, pp. 1303-1306, 2005.

[11] R. Chang, Chemistry, Eighth Edition, McGraw-Hill Higher Education, 2005, chapter 7, pp. 264-266

[12] R. Chang, Chemistry, Eighth Edition, McGraw-Hill Higher Education, 2005, chapter 9 , pp. 373-374

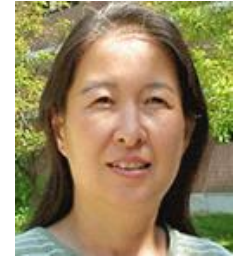

Yiwei Deng has more than 20 years of experience working in the fields of analytical chemistry and environmental chemistry. She earned her Ph.D. degree in environmental science from the Swiss Federal Institute of Technology, Zürich, Switzerland. She worked as a postdoctoral researcher in the Department of Inorganic Chemistry at the Royal Institute of Technology in Stockholm, Sweden.

She is currently an associate professor of chemistry at the University of Michigan-Dearborn and enjoys greatly teaching introductory to advanced levels of chemistry courses.

Dr. Deng's research work has been published in many professional journals including Journal of Chromatography A, Water Research, Atmospheric Environment, Analytical Methods, and Chemical Educator.

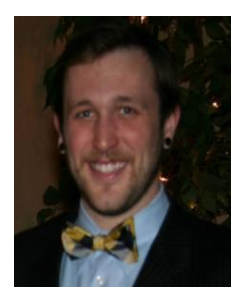

Paul Diven was born in Detroit, Michigan. In 2009 he attended Schoolcraft College- Livonia, Michigan, and then transferred to the University of Michigan-Dearborn where he graduated with BS degree in environmental science in 2014

He had a summer internship for Bloomfield Township in the Engineering and Environmenta Department and currently is an environmental technician at BT Environmental Consulting- Royal

Oak, Michigan.

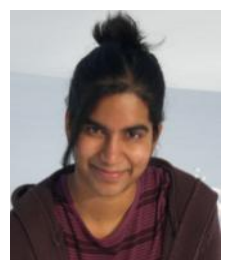

Padma Kadiyala is an undergraduate student in the biochemistry program at the University of Michigan-Dearborn and will be graduating in 2014 with a BS degree in biochemistry. In 2012, she graduated from Schoolcraft College-Livonia, Michigan with Associates in science. She is currently a laboratory assistant in the Department of Natura Sciences at the University of Michigan-Dearborn.

Her interest is improving water quality that is essentially for the functionality and sustenance of all living beings embarks her research in environmental science.

Kadiyala is a member of the Honors Transfer Innovators, Chemistry and Biochemistry Student Organizations on campus. Upon her transfer to the University of Michigan-Dearborn, she has shown great interest in scientific research. In the past year of her undergraduate studies, Kadiyala worked closely with testing the effects of inhibiting GSK-3 gene in the formation of Chicken Embryos' heart tube. Currently she works with generating knockouts of a few yeast gene sequences of Candida albicans to check their transcription regulation under various stresses. Kadiyala plans to continue her research in the fields of applied life sciences after her graduation. 

Renewable Energy 
